\title{
Transvaginal rectocele repair with human dermal allograft interposition and bilateral sacrospinous fixation with a minimum eight-year follow-up
}

\author{
Serge P. Marinkovic ${ }^{*}$ Scott Hughes, Donghua Xie, Lisa M. Gillen and Christina M. Marinkovic
}

\begin{abstract}
Background: Human dermal allografts have been used for over a decade for interpositional repair of rectoceles. How do dermal allografts perform with regards to success rate and complications with 8 years' minimum follow-up?

Methods: We retrospectively reviewed 41 consecutive patients undergoing dermal allograft interposition procedures between October 2001 and December 2005 (Repliform, Boston Scientific, Natick, MA, USA) for stage two, three, and four International Continence Society (ICS) symptomatic rectocele repairs with bilateral sacrospinous fixation. Failure was defined as recurrent stage two International Continence Society prolapse ( $A p \geq-1$ and/or $B p \geq-1$ ). All questionnaires were completed 1 week before surgery and at follow-up (September 2014 through December 2014).

Results: The mean preoperative and postoperative $A(p)$ were $0.95 \pm 0.70,-1.90 \pm 0.52$ and $B(p) 1.30 \pm 0.84,-2.13 \pm 0.51$ $(p<0.001)$. With a mean follow-up of $116.5 \pm 18.9$ months, a success rate of $73 \%(30 / 41)$ was achieved, with anatomical reduction of prolapse. For splinting and digitations, an $82 \%$ cure rate was realized. The Pelvic Floor Distress Inventory (PFDI) pre- and post-operative results showed significant improvement $(p<0.001)$. There were two incisional exposures (5\%). Seventy percent of patients were secondary repairs while $30 \%$ were primary repairs ( $81 \%$ success rate, $p<0.36)$. One patient experienced nerve entrapment and subsequent unilateral takedown. Patient satisfaction was $77 \%$.

Conclusions: Our retrospective study approaching long-term results demonstrated that symptomatic rectocele procedures with human dermal allograft interposition provide an effective anatomical and functional repair with acceptable complication rates.
\end{abstract}

Keywords: Rectocele repair, Sacrospinous fixation, Human dermal allograft

\section{Background}

Pelvic organ prolapse is a common surgical women's health care issue affecting over ten million American women, at a projected cost of two billion dollars (USD) each year [1]. Approximately $12 \%$ of adult women will eventually require surgical therapy for their symptomatic prolapse [2]. Prolapse is the result of a multitude of molecular and physiological changes that cause weakening in one or more supportive structures in the pelvic compartment. Rectal protrusions are attributed to connective

* Correspondence: urourogyn@yahoo.com

Department of Urology, Detroit Medical Center, Harper/Hutzel Hospital, Detroit, Ml 48202, USA tissue defects in the rectovaginal fascia that are level two Delancey pelvic support mechanisms. The most commonly used surgical procedures for repair in this area involve suture ligation with native tissue plication [3]. Another method of rectocele repair is defect-specific reapproximation of the rectovaginal fascia without levator plication [4, 5]. This procedure results in less postoperative pain but not much improvement in reduced rectocele recurrence.

Practitioners have tended to agree that, in the instance of transvaginal organ prolapse repairs, patients' innate connective tissue defects can be repaired with the interposition of biologic human allograft dermal material $[6,7]$

\section{Biomed Central}

(C) 2016 Marinkovic et al. Open Access This article is distributed under the terms of the Creative Commons Attribution 4.0 International License (http://creativecommons.org/licenses/by/4.0/), which permits unrestricted use, distribution, and reproduction in any medium, provided you give appropriate credit to the original author(s) and the source, provide a link to the Creative Commons license, and indicate if changes were made. The Creative Commons Public Domain Dedication waiver (http://creativecommons.org/publicdomain/zero/1.0/) applies to the data made available in this article, unless otherwise stated. 
or synthetic materials such as polypropylene [8]. Today, these biologic materials [9] abound, yet long-term studies are lacking. Available studies have multitudes of clinical criteria for evaluation and measurements for failure, making comparisons inaccurate and difficult to assess. Clinical assessments are often retrospective and include a variety of surgical approaches, so clear-cut evaluations and critiques regarding usefulness remain unclear.

Synthetic materials categorized via the Amid [10] (1997) five-material classification system have been applied to what was originally used for general surgeons' herniorrhaphy procedures and are now also applied to female pelvic prolapse surgeries (Table 1). Materials are separated into macroporous, microporous, or both, and include three well-studied materials: polypropylene, mersilene and polytetrafluoroethylene. In 2011, the Federal Drug Administration issued a stern warning against the transvaginal utilization of synthetic materials, prompting a voluntary removal of several pelvic floor reconstruction products from the market (i.e., Prolift, Gynecare, Somerset, New Jersey). As a result, surgeons were left with fewer options for transvaginal prolapse repairs. For more than 12 years, we have extensively used dermal allograft materials (Repliform, Boston Scientific, Natick, Massachusetts, USA) for symptomatic rectocele repairs with bilateral sacrospinous fixation [11-14] and now report our minimum eight-year follow-up experience with this human allograft product.

\section{Methods}

Between October 2001 and December 2005, we performed 41 consecutive symptomatic repairs with human dermal allograft interposition and bilateral sacrospinous fixation for stage two, three, or four International Continence Society rectoceles, with or without digitation and/or splinting. All rectoceles were performed with suture ligation of the new human dermal allograft fascia to the rectovaginal fascia with bilateral sacrospinous fixation. Surgeries were

Table 1 Classification of Synthetic Meshes (Amid, 1997)[10]

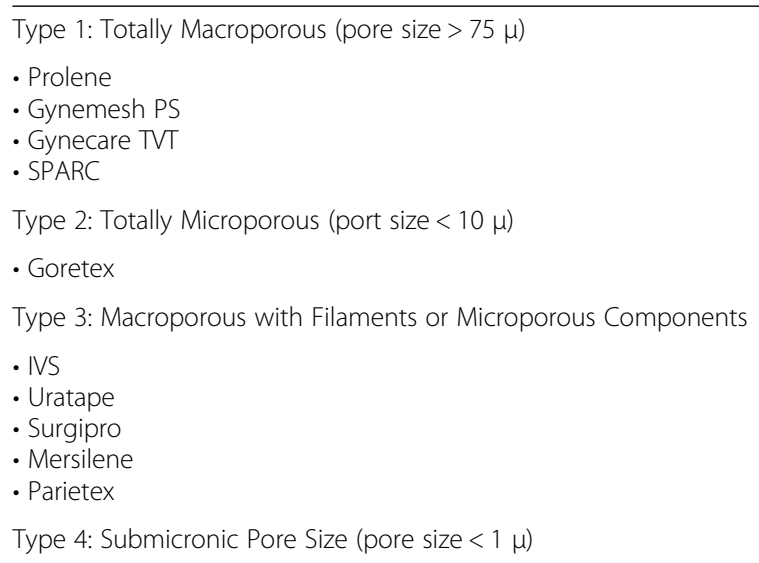

performed in their entirety by the first author. The Caprio device [11] (Boston Scientific, Natick, MA, USA) was used, with 0-polypropylene sutures (two sutures applied to the right sacrospinous ligament and another two to the left ligament). Failure was defined as recurrent International Continence Society stage two or more prolapses. All patients underwent a complete history and physical examination with International Continence Society prolapse (POP) scoring. Urodynamics were performed only if the patient was also undergoing a concomitant continence procedure performed with a tension-free vaginal tape (TVT, Gynecare, Somerset, New Jersey), tension-free vaginal tape obturator (TVTO, Gynecare, Somerset, New Jersey) or tension-free vaginal tape-Secur (Gynecare, Somerset, New Jersey, USA). Urodynamic results are not included in this study. All preoperative and postoperative data were collected between September 2014 and December 2014. Our research was performed in accordance with the Declaration of Helsinki and was approved by the Harper Hospital Institutional Review Board (Study \#033512MP4E). The Pelvic Floor Distress Inventory-20 (PFDI) [15] and the 7 point Likert Visual Analogue Scale questionnaire were used to objectively determine patient satisfaction and improvement of symptoms following surgery. On the Likert Scale (Table 2), only levels of five, six and seven were recorded as satisfactory outcomes. Levels 1-4 were recorded as unsuccessful outcomes. All patients included their age, parity, body mass index, smoking status, menopausal, hormone therapy, and prior pelvic surgery. All exposures were treated the same, with two grams of topical estrogen thrice weekly for 6 weeks. Follow-up examinations were performed by an unaffiliated, board-certified gynecologist with 30 years of experience, who was well acquainted with POPQ staging and scoring. Statistical analyses were performed using the Statistical Package for Social Sciences, version 11.0 (SPSS, Chicago, Illinois). Analyses included simple means, medians, and chi square comparisons.

\section{Results and discussion}

The mean preoperative and postoperative $\mathrm{A}(\mathrm{p})$ were $0.95 \pm 0.70,-1.90 \pm 0.52$ and $B(p) 1.30 \pm 0.84,-2.13 \pm 0.51$

Table 2 Likert Global Response Visual Analogue Scale for Rectocele Repair

Since having your rectocele repair, please rate your overall rectocele symptoms:

\begin{tabular}{lll}
\hline 1. & Markedly Worse & 1 \\
2. & Moderately Worse & 1 \\
3. & Slightly worse & 1 \\
4. & Same & 1 \\
5. & Slightly improved & 1 \\
6. & Moderately improved & 2 \\
7. & Markedly improved & 3 \\
\hline
\end{tabular}


Table 3 Patient Demographics $(n=41)$

\begin{tabular}{|c|c|}
\hline Mean Age (yrs) & $60.6 \pm 16.3$ \\
\hline Mean Follow-up (months) & $116.5 \pm 18.9$ \\
\hline Mean Parity & $2.6 \pm 2.37$ \\
\hline Mean Body Mass Index & $34.4 \pm 6.1$ \\
\hline Smoker (percent) & 34.1 \\
\hline Menopausal (percent) & 65.3 \\
\hline Post-Hysterectomy (percent) & 41.4 \\
\hline Hormone Replacement (percent) & 40.9 \\
\hline Sexually active (percent) & 24.1 \\
\hline Previous Pelvic Surgery (percent) & 70.0 \\
\hline Mean Preoperative A (p)(centimeters) ${ }^{a}$ & $0.95 \pm 0.70$ \\
\hline Mean Postoperative A (p) (centimeters) ${ }^{a}$ & $-1.90 \pm 0.52$ \\
\hline Mean Preoperative B (p)(centimeters) ${ }^{a}$ & $1.30 \pm 0.84$ \\
\hline Mean Postoperative B (p)(centimeters) ${ }^{a}$ & $-2.13 \pm 0.51$ \\
\hline Mean PreOp PFDI-20 (/300) ${ }^{a}$ & $129.6 \pm 26.7(78-223)$ \\
\hline Mean PostOp PFDI-20 (/300) ${ }^{\mathrm{a}}$ & $60.9 \pm 18.4(32-108)$ \\
\hline Biological erosion (percent) & 7.3 \\
\hline De novo dyspareunia (percent) & 17.0 \\
\hline Complication rate (percent) & 12.1 \\
\hline Patient satisfaction (percent) ${ }^{b}$ & 77.0 \\
\hline Prolapse Failure Rate (percent) ${ }^{c}$ & 27.0 \\
\hline Time to Prolapse Failure (months) & $24.7 \pm 15.3$ \\
\hline
\end{tabular}

${ }^{a}$ Changes between pre- and postoperative Pelvic Floor Distress Inventory (PFDI-20, $n=41$ ) and $\mathrm{A}(\mathrm{p})$ and $\mathrm{B}(\mathrm{p})$ were statistically significant at $p=<0.001$ at the time of patients' last follow-up

${ }^{\mathrm{b}} \mathrm{A} 7$ point Likert Global Response Scale was used, whereby responses five, six and seven were deemed successful. Numbers 1-4 were judged as failures. The $77 \%$ satisfaction rate includes only the former and not the latter 'Eleven prolapse failures: 7 Stage 2 (ICS), 3 Stage 3, and 1 Stage 4

$(p<0.001)$ (Table 3$)$. With a mean follow-up of $116.5 \pm$ 18.9 months, a success rate of $73 \%$ (30/41 patients) was achieved, with the anatomical reduction of prolapse to ICS Stage 2 or less $(A p \geq-1$ and/or $B p \geq-1)$. For splinting and digitation elimination, an $82 \%$ cure rate was realized (15/18). In the follow-up period, $13 \%(3 / 23)$ of patients complained of de novo splinting. First-time repairs demonstrated an $81 \%$ anatomical success rate while secondary repairs detailed a $70 \%$ anatomical repair. Seventy percent were secondary repair, with a $70 \%$ success rate while $30 \%$ of the patients were primary repairs (81\% success rate) $(p<0.36)$. The Pelvic Floor Distress Inventory (PFDI) pre- and postoperative results showed significant improvement $(p<0.001)$. There were three incisional exposures $(7 \%)$ of the human dermal allograft, which responded to estrogen replacement therapy for 6 to 8 weeks. One patient experienced rectal outflow obstruction and another pelvic nerve entrapment, which caused left gluteal pain. Both required re-operative take down at two and twenty weeks after rectocele repair. Patient satisfaction was $77 \%$ (Table 3). De novo dyspareunia was $17 \%$.
A review of rectocele repairs shows that, for a host of reasons, procedures without augmentation have not been successful. Pelvic floor remodeling of the supportive connective tissue continues to occur, with increased activity of collagenase and elastase enzymes [16, 17]. Elastase degradation leads to decreased connective tissue flexibility and expansion [18]. Together, these biologically enzyme processes lead to a potentially weaker pelvic floor infrastructure [18].

Native tissue amended with suture ligation and/or fixation to autologous ligaments or bone may lead to compromised clinical results because of the continual exposure to connective tissue remodeling [19-22]. Surgical treatment has seen the development of many transvaginal synthetic pelvic floor prolapse repair kits [23]. These kits have not fared as well as transvaginal stress incontinence instruments and materials, which are made of similar synthetic materials but with a more limited exposure area. [24] While stress incontinence kits are not exempt from failure or complications including exposure or erosion into the vagina or pelvic organ, in the past 5 years, prolapse repair kits have found themselves at the forefront of malpractice litigation. In the early 2000's several studies with the biological xenograft (porcine) product Pelvichol [25] (C.R. Bard, Inc. Murray Hill, New Jersey, USA) demonstrated hastened reabsorption by the body and left pelvic floor surgeons much less enthusiastic towards its use. However, experience with human dermal allograft in 2000 gave us adequate two-year and four-year data for rectocele repairs $[5,6]$ while we still used abdominal sacrocolpopexy for all multi-compartment prolapse repairs. Approaching 10 years' follow-up (116.5 \pm 18.9 months), a good success rate can be attributed to a lasting biological material and augmentation of the posterior pelvic floor compartment with a concomitant bilateral sacrospinous fixation with permanent suture. Limitations of our study included two major complications: the unilateral takedown of the rectocele repair/augmentation because of rectal outflow obstruction, and pelvic nerve entrapment, which required a unilateral takedown. These complications combined with three vaginal exposures gave us a complication rate of $12 \%$. Both patients were morbidly obese, less than five feet tall, with body mass index scores of 40 and 41.

The 11 patients who failed their surgery had a mean time to failure of $24.7 \pm 15.3$ months. At the time of their sacrocolpopexy, we carefully examined the pelvic compartment for the human dermal allograft. Quantities of tissue were still found circumscribing the periphery of the rectovaginal fascia, but the attachment to the polypropylene suture had, in most cases, pulled through from the sacrospinous ligament and/or the tissue was tattered in appearance. Of these 11, eight elected to have surgery to repair their rectoceles, but because the prolapse now involved more than one compartment, six of 
the eight elected to undergo sacrocolpopexy with anterior and posterior polypropylene mesh interposition.

Encouraging factors for the utilization of human dermal allograft include its good anatomical reduction of the rectocele, as well as symptom improvement with a follow-up in many cases exceeding 10 years. This efficacy can be considered a driving force for its continued utilization in the posterior compartment symptomatic rectocele repair; however, Level 1 and/or Level 2-1 evidence studies should be conducted to better compare the efficacy and safety of human dermal allograft to other pelvic floor materials.

\section{Conclusions}

Our retrospective study demonstrated that rectocele repairs with biological augmentation and bilateral sacrospinous fixation with a minimum 8 years' follow-up provide a good anatomical and functional repair with an acceptable complication rate.

\section{Brief summary}

Human dermal allograft interposition repair of rectoceles can be used safely and successfully, with good patient satisfaction in follow-up periods approaching 10 years.

\section{Competing interests}

The authors declare that they have no competing interests and have not received any financial remuneration from any source.

\section{Authors' contributions}

The following authors (SPM, SH, DX, LMG, CMM) all contributed equally to this paper in its writing, statistical analyses, and formatting for publication. All authors read and approved the final manuscript.

\section{Acknowledgements}

There are no acknowledgements for this paper.

Received: 17 December 2014 Accepted: 17 March 2016

Published online: 25 March 2016

\section{References}

1. Subak LL, Waetjen LE, van den Eeden S, Thom DH, Vittinghoff E, Brown JS. Cost of pelvic organ prolapse surgery in the United States. Obstet Gynecol. 2001;98(4):646-651.

2. Maher C, Feiner B, Baessler K, Adams EJ, Hagen S, Glazener CM. Surgical management of pelvic organ prolapse in women. Cochrane Database Syst Rev. 2010;14(4):CD004014. doi:10.1002/14651858.CD004014.pub4.

3. Grimes CL, Tan-Kim J, Whitcomb EL, Lukacz ES, Menefee SA. Long-term outcomes after native tissue vs. biological graft-augmented repair in the posterior compartment. Int Urogynecol J. 2012;23(5):597-604.

4. Cruikshank SH, Muniz M. Outcomes study: a comparison of cure rates in 695 patients undergoing sacrospinous ligament fixation alone and with other sitespecific procedures a 16-year study. Am J Obstet Gynecol. 2003;188(6):1509-12

5. Biehl RC, Moore RD, Miklos JR, Kohli N, Anand IS, Mattox TF. Site-specific rectocele repair with dermal graft augmentation: comparison of procine dermal xenograft (Pelvicol) and human dermal allograft. Surg Technol Int. 2008;17:174-80.

6. Kohli N, Miklos JR. Dermal graft-augmented rectocele repair. Int Urogynecol J Pelvic Floor Dysfunct. 2003;14(2):146-9.

7. Miklos JR, Kohli N, Moore R. Levatorplasty release and reconstruction of rectovaginal septum using allogenic dermal graft. Int Urogynecol J Pelvic Floor Dysfunctionct. 2002; 13(1):44-46.

8. Lo TS, Horng SG, Huang HJ, Lee SJ, Liang CC. Repair of recurrent vaginal vault prolapse using sacrospinous ligament fixation with mesh interposition and reinforcement. Acta Obstet Gynecol Scand. 2005;84(10):992-5.
9. Yurteri-Kaplan LA, Gutman RE. The use of biological materials in urogynecologic reconstruction: a systematic review. Plast Reconstr Surg. 2012; 130(5):242S-53S. doi: 10.1097/PRS.0b013e31826154e4.

10. Amid PK, Lichtenstein IL. Current assessment of Lichtenstein tension free hernia repair. Chirurg. 1997;68(10):959-64.

11. Maggiore ULR, Alessandi F, Remorgida V, Venturini PL, Ferrero S. Vaginal sacrospinous colpopexy using the Capio suture-capturing device versus traditional technique: feasibility and outcome. Arch Gynecol Obstet. 2013;287(2):267-74

12. Halaska M, Maxova K, Sottner O, Svabik K, Mlcoch M, Kolarik D, Mala I, Krofta L, Halaska MJ. A multicenter, randomized, prospective, controlled study comparing sacrospinous fixation and transvaginal mesh in the treatment of posthysterectomy vaginal vault prolapse. Am J Obstet Gynecol. 2012;207(4): 301e1-7. doi:10.1016/j.ajog.2012.08.016.

13. Paraiso MF, Barber MD, Muir TW, Walters MD. Rectocele repair: a randomized trial of three surgical techniques including graft augmentation. Am J Obstet Gynecol. 2006;195(6):1762-71.

14. Darai E, Coutant C, Rouzier R, Ballester M, David-Montefiore E, Apfelbaum D. Genital prolapse repair using porcine skin implant and bilateral sacrospinous fixation: midterm functional outcome and quality -of-life assessment. Urology. 2009;73(2):245-50.

15. Barber MD, Walters MD, Cundiff GW, Pessri trial group. Responsiveness of the pelvic floor distress inventory (PFDI) and pelvic floor impact questionnaire (PFIQ) in women undergoing vaginal surgery and pessary treatment for pelvic organ prolapse. Am J. Obstet Gynecol. 2006;194(5):1492-8.

16. Campeau L, Gorbachinsky I, Badlani GH, Andersson KE. Pelvic floor disorders: linking genetic risk factors to biochemical changes. BJU Int. 2011;108(8):1240-7.

17. Aboushwareb T, McKenzie P, Wezel F, Southgate J, Badlani GH. Is tissue engineering and biomaterials the future for lower urinary tract dysfunction (LUTD)/pelvic organ prolapse (POP)? Neurourol Urodyn. 2011;30(5):775-82.

18. Moon YJ, Choi JR, Jeon MJ, Kim SK, Bai SW. Alteration of elastin metabolism in women with pelvic floor prolapse. J Urol. 2011;185(5):1786-92. doi: 10. 1016/j.juro.2010.12.040. Epub 2011 Mar 21.

19. Kolhoff DM, Cheng EY, Sharma AK. Urological applications of engineered tissue. Regen Med. 2011;6:757-65.

20. Liang CC, Huang HY, Chang SD. Gene expression and immunoreactivity of elastolytic enzymes in the uterosacral ligaments from women with uterine prolapse. Reprod Sci. 2012;19(4):354-9.

21. Ferrari MM, Rossi G, Biondi ML, Vigano P, Dell'utri C, Meschia M. Type 1 collagen and matrix metalloproteinase 1,3, and 9 gene polymorphisms in the predisposition to pelvic organ prolapse. Arch Gynecol Obstet. 2012;285(6):1581-6.

22. Chen $B$, Yeh J. Alterations in connective tissue metabolism in stress incontinence and prolapse. J Urol. 2011;186(5):1768-72.

23. Ellington DR, Richter HE. Indications, contraindications, and complications of mesh in surgical treatment of pelvic organ prolapse. Clin Obstet Gynecol. 2013:56(2):276-88

24. Zoorob D, Karram M. Management of mesh complications and vaginal constriction: a urogynecology perspective. Urol Clin North Am. 2012:39(3):413-8.

25. Dahlgren E, Kjolhede P, RPOP-PELVICHOL study group. Long -term outcome of porcine skin graft in surgical treatment of recurrent pelvic organ prolapse. An open randomized controlled multicenter study. Acta Obstet Gynecol Scand. 2011;90(12):1393-401.

Submit your next manuscript to BioMed Central and we will help you at every step:

- We accept pre-submission inquiries

- Our selector tool helps you to find the most relevant journal

- We provide round the clock customer support

- Convenient online submission

- Thorough peer review

- Inclusion in PubMed and all major indexing services

- Maximum visibility for your research

Submit your manuscript at www.biomedcentral.com/submit 